\title{
Long-Term Outcomes of Initial Trabeculectomy in Glaucoma Associated with Granulomatous and Non-Granulomatous Uveitis
}

Faisal A. Almobarak ( $\sim$ falmobarak@ksu.edu.sa )

King Saud University https://orcid.org/0000-0003-3504-2828

Ali H. Alharbi

King Abdullah Medical City

Ibrahim Aljadaan

King Khaled Eye Specialist Hospital

Hassan Aldhibi

King Khaled Eye Specialist Hospital

\section{Research Article}

Keywords: Glaucoma, granulomatous, mitomycin-C, trabeculectomy, uveitis.

Posted Date: April 26th, 2021

DOI: https://doi.org/10.21203/rs.3.rs-372298/v1

License: (c) (i) This work is licensed under a Creative Commons Attribution 4.0 International License. Read Full License 


\section{Abstract \\ Purpose}

To evaluate the outcomes of initial trabeculectomy in granulomatous and non-granulomatous uveitis.

\section{Methods}

Retrospective comparative study of 68 eyes that underwent an initial trabeculectomy.

\section{Results}

The mean follow-up was 74.18 and 74.86 months in both groups $(p=0.95)$. The intraocular pressure decreased from $40.03 \mathrm{mmHg}( \pm 7.2)$ and $36.48 \mathrm{mmHg}( \pm 11.3)$ to $14.00 \mathrm{mmHg}( \pm 6.2)$ and $13.48 \mathrm{mmHg}$ $( \pm 5.7)$, the number of medications decreased from $3.73( \pm 0.7)$ and $3.58( \pm 0.9)$ to $1.00( \pm 1.4)$ and 1.13 $( \pm 1.4)$ on the last follow-up $(p<0.01)$ in the granulomatous and non-granulomatous groups, respectively. More eyes in the granulomatous uveitis group developed delayed postoperative complications like cataract, transient hypotony and glaucoma progression. Success rates were 64.9 and $71.0 \%$, while failure rates were 35.1 and $29.0 \%$ in both groups $(p=0.84)$.

\section{Conclusions}

Trabeculectomy seems to have comparable IOP control and survival in granulomatous and nongranulomatous uveitis. Nevertheless, more eyes in the granulomatous uveitis group developed late onset complications.

\section{Introduction}

Uveitic glaucoma is a common and potentially vision threatening complication of uveitis. ${ }^{1}$ The incidence of uveitic glaucoma among uveitis patients has been reported to be 13 to $41 \%$. ${ }^{2}$, Such variation is mostly related to the anatomic location and the wide range of uveitis entities which comprise infectious, non-infectious, idiopathic and systemic-related intraocular inflammatory conditions. ${ }^{2,4,5}$ Several mechanisms are involved in the pathogenesis of uveitic glaucoma, like the deposition of granuloma containing Langerhans giant cells and other inflammatory debris in the angle which can worsen the pressure control despite medical treatment. ${ }^{6,7}$ Granulomatous uveitis carries a greater risk of developing uveitic glaucoma ${ }^{8}$, and there is need for glaucoma surgery compared with non-granulomatous uveitis. ${ }^{9}$ Several studies reported a favorable outcome of Mitomycin C (MMC) enhanced trabeculectomy in uveitic glaucoma, but few have looked at the outcome in glaucoma associated with major uveitis entities such as granulomatous and non-granulomatous uveitis. ${ }^{10-15}$ Therefore, the aim of our study was to evaluate 
the outcomes of MMC enhanced trabeculectomy as a first procedure in patients with glaucoma associated with granulomatous and non-granulomatous uveitis.

\section{Materials And Methods}

\section{Patients}

We retrospectively reviewed the medical records of uveitic glaucoma patients who underwent MMC enhanced trabeculectomy at King Khaled Eye Specialist Hospital, Riyadh, Saudi Arabia between 2002 and 2017. Inclusion criteria were: (i) medically uncontrolled intraocular pressure (IOP) of $\geq 21 \mathrm{mmHg}$ despite maximum tolerated antiglaucoma medications; (ii) the presence of glaucomatous optic nerve head damage; (iii) no previous history of pressure lowering procedure (except for YAG peripheral iridotomy) or any intraocular surgeries; and (iv) a minimum follow-up of 12 months. Eyes were divided into two groups based on uveitis entity: granulomatous and non-granulomatous uveitis. Granulomatous uveitis was diagnosed if larger keratic precipitates, including large (mutton-fat) keratic precipitates, Koeppe/Busacca iris nodules, optic disc or choroidal granulomas were seen while non-granulomatous uveitis was diagnosed if fine endothelial keratic precipitates were seen in the absence of iris nodules and choroidal granulomas. All patients were evaluated by uveitis specialist and the inflammation was quietened ( $\leq 5$ cells per high power field in the anterior chamber) except for those who needed an urgent intervention because of uncontrolled IOP. Grading of the anterior chamber (AC) cells was done following the standardization of uveitis nomenclature scheme. ${ }^{16}$ Topical prednisolone drops were given preoperatively ranging from hourly to every 3 hours, while systemic steroids were initiated (or dose maximized for those already on the treatment) for cases of panuveitis and selected cases with intermediate uveitis based on the old history of relapses and the possible activation of the disease and then tapered and stopped (or went back to the preoperative maintenance dose) after the surgery. Systemic immunosuppressive agents were administered, maximized or maintained based on the patient presentation to achieve the optimal control of the inflammation. The dosage of all uveitis medications was gradually adjusted and tapered postoperatively to the preoperative maintenance dosage by the uveitis specialist. The study adhered to the tenets of declaration of Helsinki and was approved by the Ethics Review Board of King Khaled Eye Specialist Hospital, part of a retrospective study on trabeculectomy in uveitic glaucoma.

\section{Surgical Technique}

Fornix-based conjunctival peritomy was performed and hemostasis of the scleral bed was achieved. Scleral flap was dissected followed by the application of sponge soaked with either 0.2 or $0.4 \mathrm{mg} / \mathrm{ml}$ $M M C$, depending on the routine practice of the surgeon, under the flap and overlying Tenon tissue/conjunctiva for 2 to 5 min. Irrigation of the surgical field using balanced salt solution was carried out, then a block of tissue anterior to the scleral spur was removed followed by peripheral iridectomy. The scleral flap was closed using 10 - 0 nylon sutures and adjusted to allow adequate filtration while having a formed anterior chamber. The conjunctiva was closed using $9-0$ vicryl suture and the wound was 
checked for the presence of leakage. Finally, subconjunctival injections of antibiotics and steroids were given.

The postoperative visits considered for this study were those made at the first postoperative day, at 2 to 4 weeks and the third month, and then at 12 months intervals. Postoperative monitoring was carried out by both the glaucoma and uveitis specialists. Laser suturelysis (LSL) was performed whenever needed to enhance filtration.

\section{Data Analysis}

The following pre- and postoperative data were collected: age at time of surgery, sex, etiologic diagnosis, IOP, number of antiglaucoma medications, best corrected visual acuity (BCVA) converted into logarithm of minimal angle of resolution (logMAR) format, the need for manipulation after surgery (e.g., LSL), time to failure, postoperative complications, and the need for subsequent pressure lowering procedures to control IOP.

Variables were evaluated using the Student's t-test, Wilcoxon rank test, Mann-Whitney U test, Chi-Square test and Fisher's exact test. Cumulative probabilities of success, presented as percentage \pm standard error (SE), were determined by Kaplan-Meier life table analysis for both groups and were compared using the Mantel-Cox log rank test. Trabeculectomy success was classified as: (i) absolute success (IOP between 6 and $21 \mathrm{mmHg}$ without antiglaucoma medications, no loss of vision due to glaucoma progression, no postoperative vision threatening complications such as suprachoroidal hemorrhage and endophthalmilitis attributed to the bleb, and no need for further glaucoma procedure to control the IOP); (ii) qualified success (same as absolute success but with antiglaucoma medications); (iii) failure (if any of the following develops: IOP $>21 \mathrm{mmHg}$ despite maximum tolerated antiglaucoma medications on two visits, persistent hypotony [IOP $\leq 5 \mathrm{mmHg}$ ] on two visits causing hypotony maculopathy, loss of vision due to glaucoma progression, postoperative vision threatening complications, or the need for further glaucoma procedure to control the IOP). Variables were presented as mean and standard deviation (SD) and $p$ value less than 0.05 was considered statistically significant. Statistical analyses were performed using PAWS version 23 for Windows.

\section{Results}

Thirty-seven eyes of 25 patients in the granulomatous uveitis group and 31 eyes of 21 patients in the non-granulomatous uveitis group were included in this study. Most eyes had panuveitis in the granulomatous uveitis group while anterior uveitis was the most common anatomic location in the nongranulomatous uveitis group. The most common etiologic diagnosis was Vogt-Koyanagi-Harada disease $(\mathrm{VKH})$ and idiopathic uveitis, followed by Fuch's iridocyclitis and Behcet disease. There were no significant differences in the mean age, baseline: preoperative IOP, number of antiglaucoma medications nor log MAR between both groups. All eyes were phakic and there were no previous intraocular surgeries. There was no difference in the follow-up period between both groups $(p=0.95$, Mann-Whitney $U$ test $)$. 
Most eyes had adequate inflammatory control preoperatively ( $\leq 5$ cells per high power field in the anterior chamber) in both groups (Table 1). 
Table 1

Characteristics and ocular history*

\begin{tabular}{|c|c|c|c|}
\hline Variable & $\begin{array}{l}\text { Granulomatous } \\
\text { Uveitis } \\
(n=37)\end{array}$ & $\begin{array}{l}\text { Non-Granulomatous } \\
\text { Uveitis } \\
(n=31)\end{array}$ & $\begin{array}{l}\mathrm{P} \\
\text { value }\end{array}$ \\
\hline Age at time of surgery, yrs & $27.60( \pm 7.9)$ & $33.52( \pm 13.1)$ & 0.07 \\
\hline Gender** & $7(30.4 \%)$ & $18(78.3 \%)$ & 0.005 \\
\hline Male (23) & $16(69.6 \%)$ & $5(21.7 \%)$ & \\
\hline \multicolumn{4}{|l|}{ Female (23) } \\
\hline Uveitis location & $13(35.1 \%)$ & $13(41.9 \%)$ & 0.003 \\
\hline Anterior & Zero & $7(22.6 \%)$ & \\
\hline Intermediate & Zero & Zero & \\
\hline Posterior & $24(64.9 \%)$ & $11(35.5 \%)$ & \\
\hline \multicolumn{4}{|l|}{ Panuveitis } \\
\hline Uveitis etiology & $26(70.3 \%)$ & - & - \\
\hline VKH & $7(18.9 \%)$ & - & \\
\hline Fuchs iridocyclitis & $2(5.4 \%)$ & - & \\
\hline Posner Schlossman Syndrome & $2(5.4 \%)$ & - & \\
\hline Herpetic & - & $19(61.3 \%)$ & \\
\hline Idiopathic & - & $9(29.0 \%)$ & \\
\hline Behcet & - & $2(6.5 \%)$ & \\
\hline Ankylosing spondylitis & - & $1(3.2 \%)$ & \\
\hline \multicolumn{4}{|l|}{ JRA } \\
\hline Angle status ${ }^{\star \star \star}$ & $28(75.7 \%)$ & $17(54.8 \%)$ & 0.07 \\
\hline Open & $9(24.3 \%)$ & $14(45.2 \%)$ & \\
\hline Closed & & & \\
\hline
\end{tabular}

*Data are presented as mean $( \pm S D)$ and frequencies $(\%)$. Numbers are per eyes.

**Numbers are per patients.

*** Fisher's exact test. 


\begin{tabular}{|c|c|c|c|}
\hline Variable & $\begin{array}{l}\text { Granulomatous } \\
\text { Uveitis } \\
(n=37)\end{array}$ & $\begin{array}{l}\text { Non-Granulomatous } \\
\text { Uveitis } \\
(n=31)\end{array}$ & $\begin{array}{l}P \\
\text { value }\end{array}$ \\
\hline $\begin{array}{l}\text { MMC concentration } \\
0.2 \mathrm{mg} / \mathrm{ml} \mathrm{MMC} \\
0.4 \mathrm{mg} / \mathrm{ml} \mathrm{MMC}\end{array}$ & $\begin{array}{l}25(67.6 \%) \\
12(32.4 \%)\end{array}$ & $\begin{array}{l}19(61.3 \%) \\
12(38.7 \%)\end{array}$ & 0.59 \\
\hline $\begin{array}{l}\text { Duration of exposure to MMC } \\
\text { (minutes) } \\
0.2 \mathrm{mg} / \mathrm{ml} \mathrm{MMC} \\
0.4 \mathrm{mg} / \mathrm{ml} \mathrm{MMC}\end{array}$ & $\begin{array}{l}3.08( \pm 1.0) \\
3.08( \pm 0.7)\end{array}$ & $\begin{array}{l}2.68( \pm 0.8) \\
2.92( \pm 0.5)\end{array}$ & $\begin{array}{l}0.16 \\
0.50\end{array}$ \\
\hline $\begin{array}{l}\text { Anterior chamber cells } \\
\text { Activity of inflammation }{ }^{\star \star \star} \\
\text { Active } \\
\text { Inactive }\end{array}$ & $\begin{array}{l}0.55( \pm 0.7) \\
9(24.3 \%) \\
28(75.7 \%)\end{array}$ & $\begin{array}{l}0.58( \pm 1.2) \\
3(9.7 \%) \\
28(90.3 \%)\end{array}$ & $\begin{array}{l}0.91 \\
0.23\end{array}$ \\
\hline Follow-up, months & $74.18( \pm 41.8)$ & $74.86( \pm 42.1)$ & 0.95 \\
\hline *Data are presented as mean & frequencies (\%). & rs are per eyes. & \\
\hline $\begin{array}{l}\star \star \text { Numbers are per patients. } \\
\star \star \star \\
\text { Fisher's exact test. }\end{array}$ & & & \\
\hline
\end{tabular}

There was no significant difference between both groups in the IOP, number of antiglaucoma medications, nor logMAR throughout the whole follow-up period. The intragroup analysis revealed a statistically significant difference $(p<0.001$, Wilcoxon test) in the mean IOP and number of antiglaucoma medications compared with baseline values in both groups, but none in logMAR. Up to third of all eyes in each group required LSL within the first 4 months postoperatively to achieve adequate IOP control, but half of LSL procedures failed (Table 2). 
Table 2

Follow-up data*

\begin{tabular}{|c|c|c|c|}
\hline Characteristic & $\begin{array}{l}\text { Granulomatous } \\
\text { Uveitis } \\
(n=37)\end{array}$ & $\begin{array}{l}\text { Non-granulomatous Uveitis } \\
(n=31)\end{array}$ & P Value $* \star$ \\
\hline Preoperative baseline & $40.03( \pm 7.2)$ & $36.50( \pm 11.3)$ & 0.12 \\
\hline IOP, mmHg & $3.73( \pm 0.7)$ & $3.58( \pm 0.9)$ & 0.43 \\
\hline No. of medications & $0.60( \pm 0.7)$ & $0.61( \pm 0.7)$ & 0.94 \\
\hline LogMAR visual acuity & $9(24.3 \%)$ & $3(9.7 \%)$ & - \\
\hline Activity of inflammation & $28(75.7 \%)$ & $28(90.3 \%)$ & 0.23 \\
\hline Active & 37 & 31 & \\
\hline \multicolumn{4}{|l|}{ Inactive } \\
\hline \multicolumn{4}{|l|}{ No. of eyes } \\
\hline 1 Day postoperative & $9.92( \pm 10.2)$ & $15.08( \pm 14.8)$ & 0.10 \\
\hline IOP, mmHg & Zero & Zero & - \\
\hline No. of medications & $0.78( \pm 0.6)$ & $0.90( \pm 1.0)$ & 0.64 \\
\hline LogMAR visual acuity & $25(67.6 \%)$ & $12(38.7 \%)$ & - \\
\hline Activity of inflammation & $12(32.4 \%)$ & $19(61.3 \%)$ & 0.11 \\
\hline Active & 37 & 31 & \\
\hline \multicolumn{4}{|l|}{ Inactive } \\
\hline No. of eyes & & & \\
\hline
\end{tabular}

*Data are presented as mean $( \pm S D)$.

** $\mathrm{P}$ value calculated using unpaired student t-test, Mann-Whitney $U$ test, Fisher's exact test and ChiSquare test. 


\begin{tabular}{|c|c|c|c|}
\hline Characteristic & $\begin{array}{l}\text { Granulomatous } \\
\text { Uveitis } \\
(n=37)\end{array}$ & $\begin{array}{l}\text { Non-granulomatous Uveitis } \\
(n=31)\end{array}$ & P Value ${ }^{\star *}$ \\
\hline 1 Month postoperative & $10.08( \pm 6.3)$ & $12.15( \pm 8.0)$ & 0.24 \\
\hline IOP, mmHg & $0.05( \pm 0.3)$ & $0.06( \pm 0.4)$ & 0.90 \\
\hline No. of medications & $0.60( \pm 0.6)$ & $0.46( \pm 0.5)$ & 0.30 \\
\hline LogMAR visual acuity & $10(27.0 \%)$ & Zero & - \\
\hline Activity of inflammation & $27(73.0 \%)$ & 31 & $<0.01$ \\
\hline $\begin{array}{l}\text { Active } \\
\text { Inactive } \\
\text { No. of eyes }\end{array}$ & 37 & 31 & \\
\hline 3 Months postoperative & $12.11( \pm 7.1)$ & $12.86( \pm 6.0)$ & 0.65 \\
\hline IOP, mmHg & $0.05( \pm 0.2)$ & $0.14( \pm 0.5)$ & 0.38 \\
\hline No. of medications & $0.65( \pm 0.7)$ & $0.60( \pm 0.6)$ & 0.78 \\
\hline LogMAR visual acuity & $8(21.6 \%)$ & $6(19.4 \%)$ & - \\
\hline Activity of inflammation & $29(78.4 \%)$ & $25(80.6 \%)$ & 0.46 \\
\hline $\begin{array}{l}\text { Active } \\
\text { Inactive } \\
\text { No. of eyes }\end{array}$ & 37 & 31 & \\
\hline 12 Months postoperative & $13.76( \pm 6.2)$ & $13.97( \pm 4.6)$ & 0.88 \\
\hline IOP, mmHg & $0.46( \pm 0.8)$ & $0.42( \pm 0.9)$ & 0.85 \\
\hline No. of medications & $0.71( \pm 0.7)$ & $0.50( \pm 0.6)$ & 0.19 \\
\hline LogMAR visual acuity & $7(18.9 \%)$ & $3(9.7 \%)$ & - \\
\hline Activity of inflammation & $30(81.1 \%)$ & $28(90.3 \%)$ & 0.41 \\
\hline $\begin{array}{l}\text { Active } \\
\text { Inactive } \\
\text { No. of eyes }\end{array}$ & 37 & 31 & \\
\hline
\end{tabular}

*Data are presented as mean $( \pm S D)$.

** $P$ value calculated using unpaired student t-test, Mann-Whitney $U$ test, Fisher's exact test and ChiSquare test. 


\begin{tabular}{|c|c|c|c|}
\hline Characteristic & $\begin{array}{l}\text { Granulomatous } \\
\text { Uveitis } \\
(n=37)\end{array}$ & $\begin{array}{l}\text { Non-granulomatous Uveitis } \\
(n=31)\end{array}$ & P Value \\
\hline 24 Months postoperative & $12.55( \pm 3.7)$ & $11.52( \pm 4.2)$ & 0.39 \\
\hline IOP, mmHg & $0.59( \pm 1.1)$ & $0.59( \pm 0.9)$ & 1.00 \\
\hline $\begin{array}{l}\text { No. of medications } \\
\text { No. of eyes }\end{array}$ & 22 & 22 & - \\
\hline 36 Months postoperative & $14.97( \pm 8.2)$ & $14.45( \pm 4.4)$ & 0.81 \\
\hline IOP, mmHg & $0.71( \pm 1.0)$ & $0.75( \pm 1.2)$ & 0.91 \\
\hline $\begin{array}{l}\text { No. of medications } \\
\text { No. of eyes }\end{array}$ & 17 & 20 & - \\
\hline 48 Months postoperative & $17.89( \pm 9.1)$ & $16.55( \pm 6.8)$ & 0.61 \\
\hline IOP, mmHg & $0.78( \pm 1.1)$ & $1.11( \pm 1.4)$ & 0.42 \\
\hline $\begin{array}{l}\text { No. of medications } \\
\text { No. of eyes }\end{array}$ & 18 & 20 & - \\
\hline 60 Months postoperative & $16.08( \pm 3.6)$ & $16.40( \pm 6.6)$ & 0.88 \\
\hline IOP, mmHg & $0.75( \pm 1.2)$ & $1.33( \pm 1.6)$ & 0.30 \\
\hline $\begin{array}{l}\text { No. of medications } \\
\text { No. of eyes }\end{array}$ & 12 & 15 & -- \\
\hline Last visit & $14.00( \pm 6.2)$ & $13.48( \pm 5.7)$ & 0.73 \\
\hline IOP, mmHg & $1.00( \pm 1.4)$ & $1.13( \pm 1.4)$ & 0.69 \\
\hline No. of medications & $0.70( \pm 0.9)$ & $0.56( \pm 0.8)$ & 0.49 \\
\hline LogMAR visual acuity & $2(5.4 \%)$ & Zero & - \\
\hline Activity of inflammation & $35(94.6 \%)$ & 31 & 0.38 \\
\hline $\begin{array}{l}\text { Active } \\
\text { Inactive } \\
\text { No. of eyes }\end{array}$ & 37 & 31 & \\
\hline
\end{tabular}

*Data are presented as mean ( $\pm S D)$.

** $P$ value calculated using unpaired student t-test, Mann-Whitney $U$ test, Fisher's exact test and ChiSquare test. 


\begin{tabular}{|llll|}
\hline Characteristic & $\begin{array}{l}\text { Granulomatous } \\
\text { Uveitis } \\
(\mathbf{n = 3 7 )}\end{array}$ & $\begin{array}{l}\text { Non-granulomatous Uveitis } \\
(\mathbf{n = 3 1})\end{array}$ & P Value** \\
\hline LSL & $9(24.3 \%)$ & $9(29.0 \%)$ & 0.66 \\
No. of eyes & $4(44.4 \%)$ & $4(44.4 \%)$ & \\
Success & $5(55.6 \%)$ & $5(55.6 \%)$ & 0.84 \\
Fail & & & \\
\hline Success status at last follow- & $24 / 37(64.9 \%)$ & $22 / 31(71.0 \%)$ & \\
up & $15 / 37(40.6 \%)$ & $13 / 31(42.0 \%)$ & \\
Overall success & $9 / 37(24.3 \%)$ & $9 / 31(29.0 \%)$ & \\
Absolute success & $13 / 37(35.1 \%)$ & $9 / 31(29.0 \%)$ & \\
Qualified success & & \\
\hline Failure & & \\
\hline *Data are presented as mean $( \pm$ SD). & & \\
\hline ** P value calculated using unpaired student t-test, Mann-Whitney U test, Fisher's exact test and Chi- \\
\hline Square test.
\end{tabular}

The most common early complications during the first 2 postoperative weeks were hypotony (IOP $\leq 5$ $\mathrm{mm} \mathrm{Hg}$ ) which did not require surgical intervention, followed by IOP spike $\geq 30 \mathrm{~mm} \mathrm{Hg}$ requiring bleb massage and/or LSL in both groups. The most common delayed complication ( $>2$ weeks postoperatively) in both groups was cataract development and progression ( $p=0.11$, Chi-Square test). Among the 19 eyes in the granulomatous uveitis group, 7 eyes had early hypotony in the first postoperative week, while 2 eyes had hypotony 2-8 weeks postoperatively. In the non-granulomatous uveitis group, 2 eyes out of 10 had early hypotony in the first postoperative week, while one eye had hypotony 2-8 weeks postoperatively. The mean time to cataract surgery was $26.33( \pm 29.2)$ months (range: 6-118) and $40.90( \pm 40.0)$ months (range: 6-119) in the granulomatous and non-granulomatous uveitis groups, respectively ( $p=0.28$, Mann-Whitney $U$ test) (Table 3 ). 
Table 3

Postoperative complications*.

\begin{tabular}{|lll|}
\hline Complication & $\begin{array}{l}\text { Granulomatous Uveitis } \\
(\mathbf{n}=\mathbf{3 7})\end{array}$ & $\begin{array}{l}\text { Non-granulomatous Uveitis } \\
(\mathbf{n}=\mathbf{3 1})\end{array}$ \\
\hline Early (first 2 weeks) & $10(27.0 \%)$ & $8(25.8 \%)$ \\
\hline Transient hypotony & $2(5.4 \%)$ & $5(16.1 \%)$ \\
\hline IOP spike > 30 mmHg & $3(8.1 \%)$ & Zero \\
Hyphema & $1(2.7 \%)$ & $1(3.2 \%)$ \\
\hline Leaking bleb & $1(2.7 \%)$ & Zero \\
\hline Decompressive Retinopathy & $1(2.7 \%)$ & $1(3.2 \%)$ \\
\hline Hypotony maculopathy & $2(5.4 \%)$ & $1(3.2 \%)$ \\
\hline Choroidal effusion & & $10(32.3 \%)$ \\
\hline Delayed (more than 2 weeks) & $19(51.4 \%)$ & $2(6.5 \%)$ \\
\hline Cataract requiring surgery & $5(13.5 \%)$ & $1(3.2 \%)$ \\
\hline Loss of $\geq 3$ lines on Snellen chart & $3(8.1 \%)$ & $2(6.5 \%)$ \\
because of Glaucoma progression & $1(2.7 \%)$ & $1(3.2 \%)$ \\
\hline Delayed transient hypotony & $1(2.7 \%)$ & $1(3.2 \%)$ \\
\hline Glaucomatous complete vision loss & & \\
\hline IOP spike > 30 mmHg & Zero & \\
\hline Leaking bleb & Zero & \\
\hline Endophthalmitis & & \\
\hline *Percentages are out of each group & & \\
\hline
\end{tabular}

Complete vision loss occurred in 3 eyes at the end of the study because of progressive glaucomatous optic nerve head damage in both groups, while loss of $\geq 3$ lines on the Snellen chart was documented in 13 eyes $(35.1 \%)$ in the granulomatous uveitis groups, compared with 10 eyes $(32.3 \%)$ in the nongranulomatous uveitis group. Factors causing this drop in vision were uveitis-related retinal pathologies such as choroidal neovascular membrane and cystoid macular edema, clinically documented glaucoma progression, cataract progression and uveitis-related corneal complications such as band keratopathy (Table 4). 
Table 4

Causes of visual loss*.

\begin{tabular}{|lll|}
\hline Visual loss category & $\begin{array}{l}\text { Granulomatous Uveitis } \\
(\mathbf{n}=\mathbf{3 7})\end{array}$ & $\begin{array}{l}\text { Non-granulomatous Uveitis } \\
(\mathbf{n}=\mathbf{3 1})\end{array}$ \\
\hline Glaucomatous complete vision loss & $1(2.7 \%)$ & $2(6.5 \%)$ \\
\hline Loss of $\geq 3$ lines on Snellen chart & $5(13.5 \%)$ & $2(6.5 \%)$ \\
Glaucoma progression & $4(10.8 \%)$ & $4(12.9 \%)$ \\
Uveitis-related retinal pathologies & $3(8.1 \%)$ & $3(9.7 \%)$ \\
Cataract progression & $1(2.7 \%)$ & $1(3.2 \%)$ \\
Uveitis-related corneal complication & & \\
\hline *Percentages are out of each group & & \\
\hline
\end{tabular}

The cumulative probabilities of success of trabeculectomy for the granulomatous uveitis group were $75.5 \%( \pm 7.1 \%), 62.2 \%( \pm 8.0 \%), 54.1 \%( \pm 8.2 \%), 40.5 \%( \pm 8.1 \%)$ and $27.0 \%( \pm 7.3 \%)$ compared with $87.1 \%$ $( \pm 6.0 \%), 77.4 \%( \pm 7.5 \%), 61.3 \%( \pm 8.7 \%), 41.9 \%( \pm 8.9 \%)$ and $35.5 \%( \pm 8.6 \%)$ in the non-granulomatous uveitis group at 12, 24, 36, 48 and 60 months, respectively ( $p=0.80$, Log Rank) (Fig. 1). In the granulomatous uveitis group, the failure rate was $35.1 \%$ (13/37): 10 eyes due to uncontrolled IOP requiring further glaucoma surgery, and 3 eyes due to visual loss secondary to glaucomatous disc progression, compared with a failure rate of 29.0\% (9/31) in the non-granulomatous uveitis group: 6 eyes because of uncontrolled IOP requiring further glaucoma surgery, 2 eyes because of visual loss secondary to glaucomatous disc progression and one eye because of bleb related endophthalmitis which responded to pars plana vitrectomy and then required further glaucoma surgery $(p=0.84)$ (Table 2$)$. Most failures occurred within 3 years after trabeculectomy: $61.5 \%$ of all failed cases $\leq 24$ months and $69.2 \% \leq 36$ months of follow-up in the granulomatous uveitis group, compared with $44.4 \%$ of all failed cases $\leq 24$ months and $55.6 \% \leq 36$ months of follow-up in the non-granulomatous uveitis group. Seventeen eyes (25.0\%) required a second glaucoma procedure to control the IOP, 8 of which (11.8\% of 68 eyes) needed a third procedure, and 3 eyes ( $4.4 \%$ of 52 eyes) of these required a fourth glaucoma procedure (Table 5 ). 
Table 5

Eyes that required repeat glaucoma surgery*.

\begin{tabular}{|lll|}
\hline Glaucoma Surgery & $\begin{array}{l}\text { Granulomatous Uveitis } \\
(\mathbf{n}=\mathbf{3 7})\end{array}$ & $\begin{array}{l}\text { Non-granulomatous Uveitis } \\
(\mathbf{n}=\mathbf{3 1})\end{array}$ \\
\hline First repeat surgery & $11(29.7 \%)$ & $6(19.4 \%)$ \\
Time to surgery (from previous), months & $47.50( \pm 50.6)$ & $49.50( \pm 36.3)$ \\
Trabeculectomy \pm cataract extraction & 7 & 5 \\
Tube surgery & 2 & Zero \\
Cyclophotocoagulation & 2 & 1 \\
\hline Second repeat surgery & $6(16.2 \%)$ & $2(6.5 \%)$ \\
Proportion out of previous repeat & $6 / 11(54.5 \%)$ & $2 / 6(33.3 \%)$ \\
Time to surgery (from previous), months & $15.33( \pm 5.0)$ & $3.00( \pm 1.4)$ \\
Trabeculectomy \pm cataract extraction & Zero & Zero \\
Tube surgery & 5 & 1 \\
Cyclophotocoagulation & 1 & 1 \\
\hline Third repeat surgery & $2(5.4 \%)$ & $1(3.2 \%)$ \\
Proportion out of previous repeat & $2 / 6(33.3 \%)$ & $1 / 2(50.0 \%)$ \\
Time to surgery (from previous), months & $51.50( \pm 55.9)$ & 11.00 \\
Trabeculectomy \pm cataract extraction & Zero & Zero \\
Tube surgery & Zero & Zero \\
Cyclophotocoagulation & 2 & 1 \\
\hline *Data are presented as mean $( \pm$ SD) and frequencies $(\%)$. Numbers are per eyes. \\
\hline
\end{tabular}

\section{Discussion}

Uveitis comprises a wide range of intraocular inflammatory disorders of various aetiologies. The type, clinical associations and causes of uveitis are strongly influenced by genetic, ethnic, geographic, nutritional and environmental factors. ${ }^{17} \mathrm{MMC}$ enhanced trabeculectomy has considerably increased the success rate of glaucomas with high risk for surgical failure including uveitic glaucoma. Reports on the success rate range from 50 to $90 \%$ depending on the number of patients, the length of follow-up and uveitis entities. ${ }^{14,18-23} \mathrm{Few}$ studies evaluated the outcome of trabeculectomy in major uveitis entities such as Behcet disease and VKH while others looked at prognostic factors for surgical failure including granulomatous and non-granulomatous uveitis. ${ }^{10-15}$ To the best of our knowledge, this is the first study 
to evaluate the outcome of MMC enhanced trabeculectomy as a first glaucoma procedure in granulomatous and non-granulomatous uveitis.

In the current study, the most common causes were panuveitis and anterior uveitis in both groups, followed by intermediate uveitis in the non-granulomatous uveitis group, but no isolated posterior uveitis. This is in line with previous report on the anatomic distribution of uveitis in Saudi Arabia. ${ }^{9}, 24,25$ Nevertheless, some studies reported no difference in incidence of uveitic glaucoma in relation to anatomic classification and etiology while others found anterior uveitis as the main cause of uveitic glaucoma. ${ }^{2,8,26-29}$ The presence of anterior segment inflammation contributes to the development of glaucoma in anterior uveitis and panuveitis by directly affecting the trabecular meshwork, while aqueous outflow pathway is less influenced by posterior segment inflammation. Alrubaie et a $\mathrm{P}$ reported that glaucoma surgery was most frequent in anterior uveitis and panuveitis in 1220 eyes with uveitis in Saudi Arabia. In the current study, the most common etiologic diagnosis was VKH and idiopathic uveitis, while most patients were females and males in the granulomatous and non-granulomatous uveitis groups, respectively. This is not surprising given that VKH was among the commonest uveitis entities in females in Saudi Arabia while idiopathic was the commonest among males. ${ }^{24}$ Most eyes had open angle in both groups while few had closed angles. The accumulation of fibrotic tissue, granuloma containing Langerhans giant cells and other inflammatory debris in the trabecular meshwork and Schlemm's canal can obstruct the angle and result in either open or closed angle, and might block the trabeclectomy filtration site. ${ }^{7,14}$

Most patients in our study had a controlled inflammation before trabeculectomy and during the first 12 months after surgery, apart from the surgically induced inflammation, except for an increase in the first month in the granulomatous uveitis group in comparison with the non-granulomatous uveitis group. Inflammatory mediators present in aqueous during active inflammation and filtering to the subconjunctival space result in macrophages and fibroblasts activation, aggregation, collagen synthesis and eventual scarring. Interestingly, there was no difference in the immediate postoperative complications between both groups. Hypotony and IOP spikes were the most common early postoperative complications in both groups, while more eyes in the granulomatous uveitis groups developed more delayed complications compared with the non-granulomatous uveitis group mainly: cataract progression requiring surgery (51.4 and 32.3\%), visual loss because of glaucoma progression (13.5 and 6.6\%) and transient hypotony (8.1 and 3.2\%). Yalvac et a ${ }^{10}$ reported cataract $(23.1 \%)$ and bleb leak $(15.3 \%)$ as the most common complication after trabeculectomy in Behcet disease (a major nongranulomatous uveitis entity), while choroidal effusion and hypotony were 11.5 and $7.6 \%$, respectively in a study that included 26 eyes. Elgin et a/ ${ }^{2}$ reported cataract development in $30.4 \%$ of 23 eye after trabeculectomy in Behcet disease and hypotony $26.1 \%$. Iwao et a ${ }^{14}$ reported similar rates of cataract requiring surgery in 30 eyes (29.7\%) out of 101 eyes with uveitic glaucoma which included 81 eyes (80.2\%) with non-granulomatous uveitis, but lower rates of hypotony. Such results are almost comparable to our non-granulomatous uveitis group results. Complications in the granulomatous uveitis group are also comparable to our previous report on VKH (a major granulomatous uveitis entity), while Shimizu et 
$a l^{13}$ reported lower rates of hypotony and choroidal detachment, bleb leak, and cataract requiring surgery in 47 eyes, 32 (68.1\%) of whom had granulomatous uveitis, compared with the granulomatous uveitis group in our current study. ${ }^{11,13}$ One eye developed endophthalmitis in the non-granulomatous uveitis group but with no signs of leakage on presentation. Bleb leak can be asymptomatic and could spontaneously seal due to the presence of infection and concurrent inflammation. ${ }^{30,31}$ The high percentage of cataract development and progression in uveitic glaucoma is not only due to the cataractogenic effect of trabeculectomy, but also the presence of chronic inflammation and use of topical corticosteroids therapy. ${ }^{32-35}$ Other additional factors include old age and hypotony. The current study included patients of relatively younger age group (27.85 and 31.78 years in both groups). However, $28.57 \%$ and $33.33 \%$ of eyes which developed early hypotony had cataract development and progression in the granulomatous and non-granulomatous groups, respectively.

There were no differences between both groups in the IOP, number of antiglaucoma medications, trabeculectomy survival nor the success rates and failures. Both groups had similar follow-ups, therefore, it is unlikely that the natural course of trabeculectomy could have influenced either group outcome over the other. ${ }^{19,36,37}$ Elgin et al ${ }^{2}$ reported $82.6 \%$ success rate in 23 eyes with Behcet disease at one year follow up while Yalvac et al ${ }^{10}$ reported $83.3 \%$ and $66.4 \%$ success rates in 26 eyes with Behcet disease at one and 4 years, respectively. Shimizu et a $l^{13}$ reported a success rate of about $60 \%$ in 15 eyes with nongranulomatous uveitis in 2 to 10 years follow-up period (thirty-four eyes out of 47 underwent trabeculectomy, while the remaining eyes underwent trabeculotomy and trabectome surgery). However, Iwao et al ${ }^{14}$ reported $94.4 \%$ success rate of 57 eyes at one year and $85.6 \%$ and around $80.0 \%$ in 39 and 19 eyes at 2 and 3 years, respectively. Our short term success rates are comparable to previous studies but the intermediate and long term rates are lower. ${ }^{10,12-14}$ Shimizu et al ${ }^{13}$ reported a success rate of $90 \%$ in 32 eyes with granulomatous uveitis on the first year and $87.5 \%$ in 2 to 10 years follow-up, while Iwao et al $l^{4}$ reported $72.4 \%$ success rate in 15 eyes at one year, and $54.3 \%$ at 2 years in 8 eyes. In our previous report on $\mathrm{VKH}$, the success rates were $77.8 \%, 74.1 \%$ and $63.0 \%$ on the first, second and third years, respectively. Similarly, our success rates in the current study are lower than previous reports (Fig. 2).

Most repeat glaucoma surgeries were done less than 3 years after the initial trabeculectomy, half of the first repeats need a second repeat glaucoma surgery. Our results are in line with Carreño et a ${ }^{\beta 8}$ who reported a higher risk of failure of repeat glaucoma surgery in comparison to the first procedure. ${ }^{38}$ In the study of Elgin et al ${ }^{12}, 4$ eyes with Behcet disease (17.4\%) required a repeat glaucoma surgery which is comparable to our non-granulomatous uveitis group. In our previous study on $\mathrm{VKH}, 8$ eyes $(29.6 \%)$ required a repeat glaucoma surgery which is comparable to our granulomatous uveitis group. ${ }^{11,12}$

This study has some limitations which include retrospective design, relatively small sample sizes and the non-standardized surgical technique and follow-up treatment. Collected data were limited to what were available in medical records. However, this is the first study to evaluate the outcome of trabeculectomy in eyes with uveitic glaucoma in two major uveitis entities with a long follow-up. In conclusion, MMCenhanced trabeculectomy seems to have comparable outcomes in glaucoma associated with 
granulomatous and non-granulomatous uveitis. More eyes in granulomatous uveitis groups developed late onset complications, while most failure and repeat glaucoma surgeries in both groups occurred in the first 3 years. Therefore, continuous monitoring after trabeculectomy is crucial in both granulomatous and non-granulomatous uveitis.

\section{Declarations}

\section{Acknowledgment: None}

Competing Interests: None

\section{Funding: None}

Study Data: The authors confirm that the data supporting the findings of this study are available within the article

\section{References}

1. Siddique SS, Suelves AM, Baheti U, et al. Glaucoma and uveitis. Surv Ophthalmol 2013;58(1):1-10.

2. Takahashi T, Ohtani S, Miyata K, et al. A clinical evaluation of uveitis-associated secondary glaucoma. Jpn J Ophthalmol 2002;46(5):556-62.

3. Heinz C, Koch JM, Zurek-Imhoff B, et al. Prevalence of uveitic secondary glaucoma and success of nonsurgical treatment in adults and children in a tertiary referral center. Ocul Immunol Inflamm 2009;17(4):243-8.

4. Hwang DK, Chou YJ, Pu CY, et al. Risk factors for developing glaucoma among patients with uveitis: a nationwide study in Taiwan. J Glaucoma 2015;24(3):219-24.

5. Weiner A, BenEzra D. Clinical patterns and associated conditions in chronic uveitis. Am J Ophthalmol 1991;112(2):151-8.

6. Moorthy RS, Mermoud A, Baerveldt G, et al. Glaucoma associated with uveitis. Surv Ophthalmol 1997;41(5):361-94.

7. Hamanaka T, Takei A, Takemura T, Oritsu M. Pathological study of cases with secondary open-angle glaucoma due to sarcoidosis. Am J Ophthalmol 2002;134(1):17-26.

8. Merayo-Lloves J, Power WJ, Rodriguez A, et al. Secondary glaucoma in patients with uveitis. Ophthalmologica 1999;213(5):300-4.

9. Al Rubaie K, Al Dhahri H, Al Fawaz A, et al. Incidence and Risk Factors for Developing Glaucoma Among Patients with Uveitis in a University-based Tertiary Referral Center in Riyadh, Saudi Arabia. Ocul Immunol Inflamm 2016;24(5):571-8.

10. Yalvac IS, Sungur G, Turhan E, et al. Trabeculectomy with mitomycin-C in uveitic glaucoma associated with Behcet disease. J Glaucoma 2004;13(6):450-3. 
11. Almobarak FA, Alharbi AH, Morales J, Aljadaan I. Outcomes of Trabeculectomy With Mitomycin-C in Uveitis Associated With Vogt-Koyanagi-Harada Disease. J Glaucoma 2016;25(6):528-32.

12. Elgin U, Berker N, Batman A, Soykan E. Trabeculectomy with mitomycin $\mathrm{C}$ in secondary glaucoma associated with Behcet disease. J Glaucoma 2007;16(1):68-72.

13. Shimizu A, Maruyama K, Yokoyama Y, et al. Characteristics of uveitic glaucoma and evaluation of its surgical treatment. Clin Ophthalmol 2014;8:2383-9.

14. Iwao $\mathrm{K}$, Inatani $\mathrm{M}$, Seto $\mathrm{T}$, et al. Long-term outcomes and prognostic factors for trabeculectomy with mitomycin C in eyes with uveitic glaucoma: a retrospective cohort study. J Glaucoma 2014;23(2):8894.

15. Komae K, Takamoto M, Tanaka R, et al. Initial Trabeculectomy With Mitomycin-C for Secondary Glaucoma-associated With Uveitis in Behcet Disease Patients. J Glaucoma 2017;26(7):603-7.

16. Jabs DA, Nussenblatt RB, Rosenbaum JT, Standardization of Uveitis Nomenclature Working G. Standardization of uveitis nomenclature for reporting clinical data. Results of the First International Workshop. Am J Ophthalmol 2005;140(3):509-16.

17. Chang JH, Wakefield D. Uveitis: a global perspective. Ocul Immunol Inflamm 2002;10(4):263-79.

18. Park UC, Ahn JK, Park KH, Yu HG. Phacotrabeculectomy with mitomycin C in patients with uveitis. Am J Ophthalmol 2006;142(6):1005-12.

19. Noble J, Derzko-Dzulynsky L, Rabinovitch T, et al. Outcome of trabeculectomy with intraoperative mitomycin C for uveitic glaucoma. Can J Ophthalmol 2007;42(1):89-94.

20. Kaburaki T, Koshino $\mathrm{T}$, Kawashima $\mathrm{H}$, et al. Initial trabeculectomy with mitomycin $\mathrm{C}$ in eyes with uveitic glaucoma with inactive uveitis. Eye (Lond) 2009;23(7):1509-17.

21. Dupas B, Fardeau C, Cassoux N, et al. Deep sclerectomy and trabeculectomy in uveitic glaucoma. Eye (Lond) 2010;24(2):310-4.

22. Almobarak FA, Alharbi AH, Morales J, et al. Intermediate and Long-term Outcomes of Mitomycin Cenhanced Trabeculectomy as a First Glaucoma Procedure in Uveitic Glaucoma. J Glaucoma 2017;26(5):478-85.

23. Bettis DI, Morshedi RG, Chaya C, et al. Trabeculectomy With Mitomycin C or Ahmed Valve Implantation in Eyes With Uveitic Glaucoma. J Glaucoma 2015;24(8):591-9.

24. Al Dhahri H, Al Rubaie K, Hemachandran S, et al. Patterns of Uveitis in a University-based Tertiary Referral Center in Riyadh, Saudi Arabia. Ocul Immunol Inflamm 2014:1-9.

25. Al Dhibi HA, Al Shamsi HN, Al-Mahmood AM, et al. Patterns of Uveitis in a Tertiary Care Referral Institute in Saudi Arabia. Ocul Immunol Inflamm 2016:1-8.

26. Sijssens KM, Rothova A, Berendschot TT, et al. Ocular hypertension and secondary glaucoma in children with uveitis. Ophthalmology 2006;113(5):853-9 e2.

27. Herbert HM, Viswanathan $A$, Jackson $\mathrm{H}$, et al. Risk factors for elevated intraocular pressure in uveitis. J Glaucoma 2004;13(2):96-9.

28. Kok H, Barton K. Uveitic glaucoma. Ophthalmol Clin North Am 2002;15(3):375-87, viii. 
29. Neri P, Azuara-Blanco A, Forrester JV. Incidence of glaucoma in patients with uveitis. J Glaucoma 2004;13(6):461-5.

30. DeBry PW, Perkins TW, Heatley G, et al. Incidence of late-onset bleb-related complications following trabeculectomy with mitomycin. Arch Ophthalmol 2002;120(3):297-300.

31. Belyea DA, Dan JA, Stamper RL, et al. Late onset of sequential multifocal bleb leaks after glaucoma filtration surgery with 5-fluorouracil and mitomycin C. Am J Ophthalmol 1997;124(1):40-5.

32. Investigators A. The Advanced Glaucoma Intervention Study: 8. Risk of cataract formation after trabeculectomy. Arch Ophthalmol 2001;119(12):1771-9.

33. Sung VC, Barton K. Management of inflammatory glaucomas. Curr Opin Ophthalmol 2004;15(2):13640.

34. Molteno AC, Bosma NJ, Kittelson JM. Otago glaucoma surgery outcome study: long-term results of trabeculectomy-1976 to 1995. Ophthalmology 1999;106(9):1742-50.

35. Mills KB. Trabeculectomy: a retrospective long-term follow-up of 444 cases. $\mathrm{Br} \mathrm{J}$ Ophthalmol 1981;65(11):790-5.

36. Chen PP, Weaver YK, Budenz DL, et al. Trabeculectomy function after cataract extraction. Ophthalmology 1998;105(10):1928-35.

37. Ehrnrooth P, Lehto I, Puska P, et al. Phacoemulsification in trabeculectomized eyes. Acta Ophthalmol Scand 2005;83(5):561-6.

38. Carreno E, Villaron S, Portero A, et al. Surgical outcomes of uveitic glaucoma. J Ophthalmic Inflamm Infect 2011;1(2):43-53.

\section{Figures}




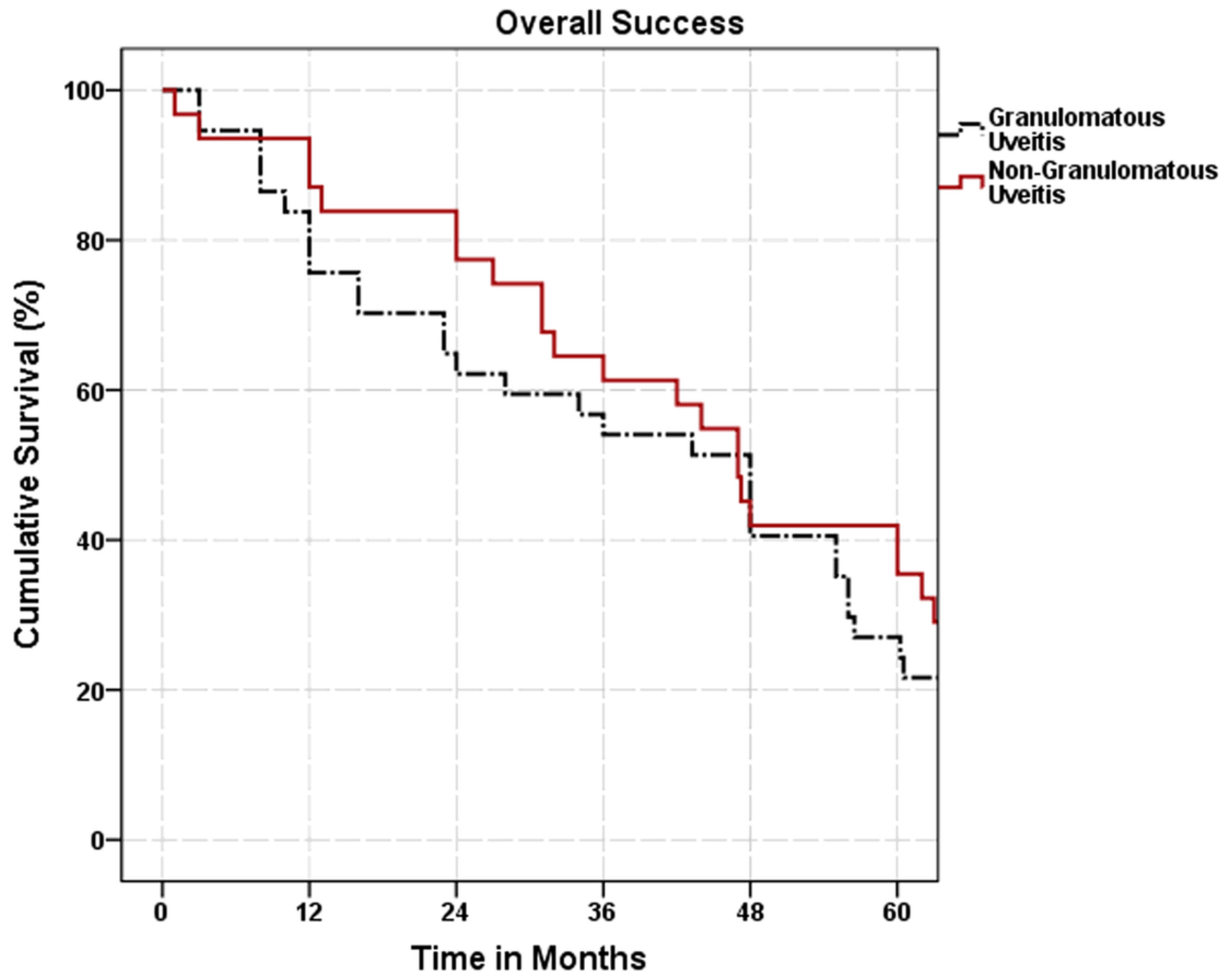

Figure 1

Kaplan-Meier survival curves showing the cumulative probability of success. 


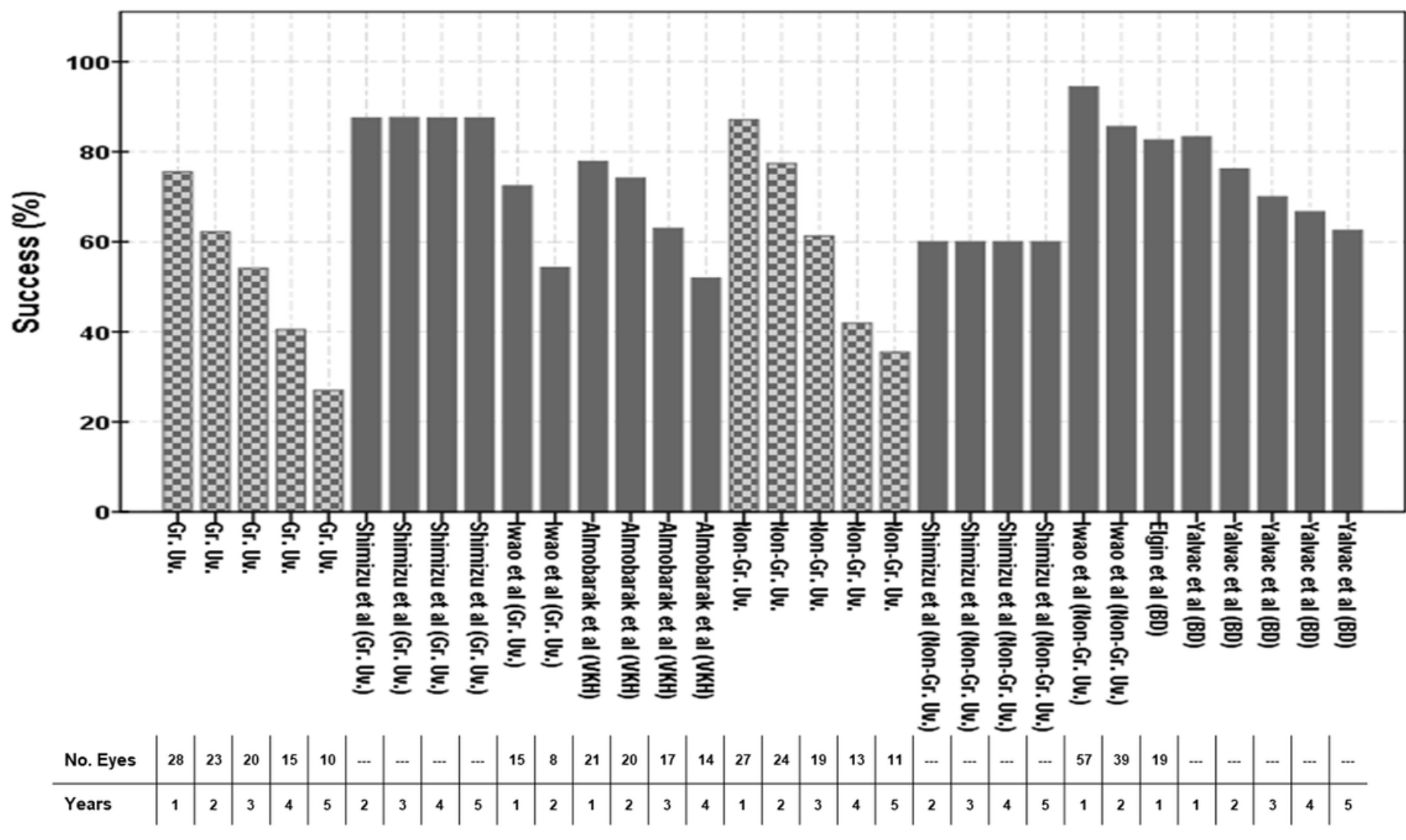

Figure 2

Bar chart comparing the success rates in different studies with the current study. Dark bars represent studies on trabeculectomy while light dotted bars represent the current study. Gr. Uv. : Granulomatous Uveitis. Non-Gr. Uv. : Non-Granulomatous Uveitis. BD: Behcet disease. VKH: Vogt-Koyanagi-Harada disease. 